\title{
THE MEDICAL CONDUCT OF A BROTHEL
}

\author{
BY \\ F. RAY BETTLEY
}

A few years ago I found myself in the position of exercising indirect medical observation on three large brothels. I was able, at that time, to find no accounts of others who had been similarly placed; records of this kind might have considerable epidemiological value, and it is their scarcity which prompts the present report.

The brothel which forms the subject of this report, the largest of the three mentioned, was established in a large city frequented by troops of an occupying force in a country where organized prostitution was illegal. The existence of these particular brothels was tolerated by the civil police on certain conditions, the chief of which was that the military police of the occupying army should be entirely responsible for their supervision and orderly conduct. In that country the civil police appeared to have somewhat wider powers than in the United Kingdom, and though other brothels carried on a clandestine existence they were frequently raided and closed, while street-walkers could be arrested and summarily convicted. In spite of these measures, however, casual prostitution and clandestine brothels were considerably more widespread than in most European countries.

The legal immunity thus conferred on the women in the tolerated brothels was therefore eagerly sought after. In these houses the word of the military police was law; women could be suspended or dismissed (indeed the whole house could be closed at an hour's notice), and all concerned knew that as soon as the support of the military police authority was withdrawn the civil police would take action. This situation made for strict discipline on the part of the keepers, the civilian doctor, and the women themselves. There can be little doubt that there was a high standard of obedience to the rules made by the military authority.

\section{Premises}

This was a large old house situated in a slummy quarter near the centre of the city, with one single entrance from the street. The ground floor was entirely taken up by a large vestibule in which clerks and military police were on duty and by the rooms used for preventive ablution. The latter will be described separately. Above this were three floors each comprising a small landing-lounge, two or three water closets, and about a dozen rooms. All this accommodation was plainly and rather unattractively furnished.

\section{Staff}

Military.-The conduct of the house was the responsibility of the military police authority of the area. At least six military policemen of various grades were constantly on duty in the house and were normally stationed in the vestibule. Two clerks were also on duty in the vestibule and either four or five orderlies (not medical orderlies) in the preventive ablution rooms.

A military venereologist assisted the chief of military police at some of his routine inspections of the premises and supervised the work of the civil doctor.

Civil-The brothel was kept by a middle-aged woman who received certain instructions from the chief of military police and was responsible to him for carrying them out. She employed at her discretion a variable number of male and female staff (usually four or five) as cleaners and sweepers.

The number of prostitutes employed varied from thirty to forty, and with the latter number usually about thirty-five would be at work on any given day. When a new prostitute was to be employed the keeper first proposed her to the military authority, who, with the aid of the civil police, investigated her origin, identity, and record. Those with a criminal record or similar undesirable feature were permanently excluded. The remainder were then "vetted" from the aspect of military security, and if they satisfied the requirements of the chief of military police, a dossier was opened for them and they were subjected to medical examination. If this in turn proved satisfactory their employment was sanctioned by the military police authority.

The women were of various racial-mixtures. Their ages appeared to lie between about 18 and 40 , and though uneducated they seemed to have a fair understanding of hygiene as applied to their own trade. 
The medical surveillance of the women was carried out by a civilian doctor of considerable experience in the diagnosis of venereal disease, and the standards he adopted were high. Materials for pathological examination were sent to an independent private laboratory.

\section{Conduct}

The only clients admitted were soldiers, sailors, and airmen of the occupying force. The police appropriate to their service were responsible for maintaining discipline among them and excluding any who were seriously the worse for drink. The effect of this rule was to exclude any men likely to cause a disturbance ; it seldom, if ever, resulted in men thus excluded being obliged to consort with clandestine prostitutes. Any complaint of quarrelling, dishonesty, or similar behaviour against a woman could result in her immediate suspension. The women, for their part, could lodge complaints against men or against the keeper of the house with the military police, and disputes of this kind were dealt with by the military police chief himself. In fact, disciplinary disturbances of any kind, either on the part of men or of women, were quite unusual and were never serious.

The sale of bottled non-alcoholic drinks at controlled prices was allowed, but otherwise no food or drink or other article could be sold. Music, dancing, and other entertainments were forbidden. A hygiene and general inspection of the house was carried out by a senior warrant-officer of the military police at least once a day. The chief of military police himself and a military medical officer inspected less often and at irregular intervals. All instructions regarding hygiene and general conduct were in fact carried out most expeditiously and a very reasonable standard of hygiene, including even-mirabile dictu-apparent absence of Cimex lectularius, was achieved.

\section{Prophylaxis}

Men.-Two large preventive ablution rooms were situated on the ground floor, one on each side of the vestibule, so that each man passed their open doors as he left the house. They conformed to the usual pattern and between them there was room for about twenty men to use them at any one time.

The chemicals used were 1:4,000 permanganate solution and 33 per cent. calomel cream. The rooms were well equipped and excellently run by

five orderlies, and while their use was not obligatory the police on duty were instructed to use their influence to ensure that as many as possible took this precaution.

The preventive ablution rooms were also available to " outsiders" who had not used the brothel but had risked infection elsewhere. Such men, however, formed a very small proportion of the total who passed through.

Women.-The women were instructed to ascertain as far as they could that their contacts were not infected, and they knew that an allegation of infection acquired from them meant instant suspension.

Condoms were supplied free to the women and in each room was exhibited a notice advising their use. In addition, each room was equipped with a douche-can apparatus and bidet with 1:4,000 permanganate solution ad lib. A washstand with soap and water and towel were in every room.

No accurate information is available about the extent to which the women took advantage of these precautions but it is believed that they were not by any means always used.

\section{Records}

On entering the house, the client first saw the clerk in the vestibule who recorded some identifying particulars of the man. This was not strictly enforced ; usually the man's number was recorded, but if he was unwilling to give it, a Christian name was accepted instead. He then paid the controlled price and was given a receipt-tally. Going upstairs, he gave the receipt-tally to the woman he chose and she gave him in exchange a tally bearing her own personal number. When the man returned to the vestibule this tally was taken by the clerk and the man retained a blue slip bearing the date and the number of the woman. He was advised to keep the blue slip for a few weeks " in case he got venereal disease," to produce to the medical officer should he be infected. He was then advised to use the preventive ablution facilities.

In the preventive ablution room a record of total attendances was kept, and when possible the man's personal number was recorded, but no record was made on the blue slip.

A personal dossier for each woman was kept by the military police and with this was her medical record, strictly recording all routine examinations and their results.

\section{Medical Inspections}

Medical examination of new women before their employment was carried out entirely by the civilian doctor. During employment women were examined once a week by this doctor, and daily by the keeper of the house. The latter examination was quick but surprisingly thorough, and would probably have been sufficient to detect any clinical signs of recent infection. 
Medical Standards Adopted.-These were laid down by the military venereologist of the district and very rigidly adhered to. In the few cases where doubt arose or where routine procedure seemed inapplicable the venereologist was consulted, and he made his decision from the data contained in the medical record. This officer had himself no concern in the examination of women. The rules laid down vere as follows.

BEFORE- ENTRANCE.-The women had to be clinically normal, with blood Wassermann and Kahn tests and blood gonococcal complement fixation test all negative. Urethral and cervical smears had to be negative three times, and cultures negative once ; at the next menstruation, four premenstrual and four postmenstrual smears; including one culture, had all to be negative.

DURING Work.-Blood Wassermann and Kahn tests were done once a month, and urethral and cervical smears at the weekly examination.

STOPPAGE.-If at any time clinically suspicious signs appeared the military police were informed and the woman stopped work at once. Similarly if positive or doubtful pathological reports on routine tests were received the woman was immediately suspended.

The great majority of men using the house were referred to the same military venereologist if they contracted venereal disease. If they claimed to have been infected at the brothel they were asked for the number of the woman concerned and if possible for the blue slip. If the number was forthcoming the woman at once stopped work.

After having been stopped, the woman could at any time request clearance tests and apply for re-employment.

RE-EMPLOYMENT AFTER STOPPAGE.-Conditions of reemployment were as follows.

Gonorrhoea.-Blood gonococcal fixation test, "four premenstrual and four postmenstrual smears, including one culture, both urethral and cervical, all had to be negative.

Chancroid, Erosions, etc.-Clinical healing was necessary, and blood Wassermann and Kahn tests taken fortnightly for six weeks all had to be negative.

Syphilis.-Syphilis had to be treated under the woman's own arrangements until she was clinically normal and blood Wassermann and Kahn tests were normal. ' Full tests were then made as for a new applicant ; the woman could then'start work provided a further course of treatment was begun within a month, the course consisting of not less than $5.5 \mathrm{~g}$. neoarsphenamine and $1.5 \mathrm{~g}$. of bismuth in divided doses given over a period of not more than ten weeks. If this course of treatment was interrupted for any reason, the woman was instantly suspended.

Condylomata. - The woman could be re-employed if she was clinically cured: if a relapse occurred, the woman was permanently excluded.

Provision was also made for women who were absent from the routine inspections.
In this, as in other respects, the liaison between the military police and the venereologist was close and cordial.

\section{Results}

It is understandable that it was not possible to carry out a routine follow-up on men who had visited the brothel. It so happened, however, that all men reporting sick with venereal disease in the district were sent to the same hospital and seen by the same venereologist, so that records are reasonably complete. No doubt some left the district during their incubation period, and it is not unreasonable to suppose that some concealed their disease and obtained treatment from unofficial sources. It is, however, unlikely that these formed a large proportion of the whole. Every man reporting with venereal disease at the hospital was asked where he had contracted it, and if he claimed the brothel as the source of infection the case is here recorded as such, whether or not the blue slip was produced in proof of his statement. For this reason the number of brothel infections given is liable to be somewhat higher than the true figure. On the other hand it is highly improbable that a man who had been infected in the " semi-official " brothel would have claimed infection from a clandestine and illegal source. For these reasons it is believed that the figures given below, though not strictly accurate, give a reasonably correct assessment of the true position.

During the first eight months of the year, 277,482 men used the brothel, and of these 248,593 (89 per cent.) used preventive ablution. Over this period eighty-seven men suffering from venereal disease claimed this brothel as the source of their infectiona rate of 0.31 per 1,000 .

In only five cases where the number of the woman was given was she found after careful and repeated examination to be infected. My records do not indicate how often the same woman was named as a source of infection by more than one man. This was certainly a rare event, but about the same time two men, at intervals of a few days, named a certain girl from another brothel as a source of syphilis ; the most stringent tests failed to reveal any sign of infection in this girl.

During the months of May and June a somewhat more detailed inquiry was made which involved obtaining information from infected men. In each case the man was asked : (1) where he contracted the disease (in brothel or by casual exposure outside); (2) whether he was under the influence of alcohol at the time; (3) whether a condom was used; (4) whether preventive ablution was used. The nature of the disease contracted was also recorded. 
These questions were asked by the venereologist at the end of the clinical examination ; usually no third party was present, and care was taken to obtain an honest answer as far as possible. The clinical interview was carried out with the intention of obtaining the patient's confidence, and in asking the questions care was taken not to imply that truthful answers would in any way result in penalization. If a patient showed unwillingness to answer any question, he was not pressed and his case was omitted from the figures. While, therefore, histories obtained from such patients are notoriously inaccurate, it is believed that they are in this series as good as most that could be collected from such subjects.

Some comment on the replies is required.

Mode of Contraction.-The brothel referred to in each case is the one above described. If exposure took place in a clandestine establishment or in any other circumstances it is here recorded as "casual." Little information is available as to such casual exposure. Prostitution was subject to legal penalties and the police were reasonably active in this regard. Clandestine brothels were, therefore, probably few, and it is most unlikely that any were subject to medical inspection of any sort. Individual prostitutes haunted cabarets, cafés, and the streets. They were for the most part of similar type and origin to those working in the brothel ; the conditions under which they lived and plied their trade were often extremely insanitary and filthy. Information'as to disease rates in these women is not available.

Alcoholism.-No strict standard of alcoholism was adopted. The patient was asked, " Had you been drinking at the time?" If he replied in the affirmative he is recorded as " alcoholic" regardless of the quantity of alcohol he had taken.

Condoms.-Condoms were in most cases obtainable through army camps and were usually of Italian manufacture. Some would perhaps have been subject to inspection to see that they had not deteriorated, but this would not usually be so. In the brothel, periodic examination of condoms taken at random from stock was carried out.

Preventive Ablution.-Preventive ablution was provided in units and standing camps. Such preventive ablution centres were subject to inspection by army medical officers, and their quality varied a good deal. A supervising orderly was sometimes but not always available, and the efficiency of preventive ablution varied a great deal. Permanganate solution and calomel cream were provided. In a case of casual exposure it was seldom that a man carried out preventive ablution until he arrived back at his unit, and a delay of a few hours was liable to occur. On inquiry it was found that very few men carried out preventive ablution after a lapse of more than an hour following exposure ; these cases are recorded as not having carried out preventive ablution, because it was reckoned that after such a delay preventive ablution would not be likely to be effective.

Disease Contracted.-The diagnosis of gonorrhœa was confirmed bacteriologically ; that of syphilis by dark-ground examination or, in some cases, serologically according to accepted standards. The diagnosis of "venereal sore" was made by exclusion and confirmed by subsequent observation. It excluded syphilis, scabies, - traumatic ulcers, herpes progenitalis, and erosive balanitis ; almost all cases in this group were of chancroid (Ducrey).

One hundred and twenty-seven patients were questioned and recorded in this way, and are dealt with in the statistical analysis. The figures given by the military police for the numbers of men using the brothel during these months were ascertained and are included in the detailed analysis.

\section{Statistical Analysis}

Nature and Collection of Data._-Personal information was invited from patients who presented themselves at the venereal disease department of a military hospital over a period of two months and of certain figures obtained from the military police. The questions were :

1. Was the exposure a brothel or a casual one ?

2. Was the patient under the influence of alcohol, or not, at the time of exposure?

3. Was a condom used or not?

4. Was preventive ablution used or not?

The disease contracted-venereal sore (V.S.), gonorrhœa (G), or syphilis (S) was also noted.

The military police authorities' figures gave the numbers of men who used the brothel during the two months, and the numbers of these who used its preventive ablution rooms.

Method of Analysis. - The patients we have studied are all for whom information is available, and there is no systematic sampling from a larger population. Inferences from the sample to a larger population must therefore be viewed with reserve; but in this connexion all we can say is that we know of no special conditions obtaining at the time of the investigation that would cast positive doubt on the representativeness of the sample.

The number of possible groupings of patient (such as (i) In alcoholics, syphilis, used preventive ablution, used 
TABLE I

RESULTS OF QUESTIONING

\begin{tabular}{|c|c|c|c|c|c|c|c|c|c|c|c|c|c|c|c|}
\hline \multicolumn{5}{|c|}{-} & \multirow{2}{*}{ 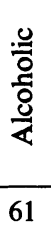 } & \multirow{2}{*}{ 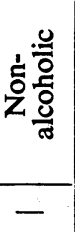 } & \multirow{2}{*}{ 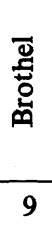 } & \multirow{2}{*}{ 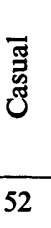 } & \multirow{2}{*}{$\frac{\substack{g \\
0 \\
0 \\
0}}{12}$} & \multirow{2}{*}{ 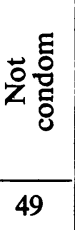 } & \multirow{2}{*}{$\frac{\stackrel{0}{: 20}}{11}$} & \multirow{2}{*}{ 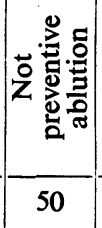 } & \multirow{2}{*}{ 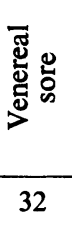 } & \multirow{2}{*}{ 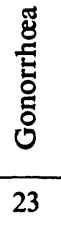 } & \multirow{2}{*}{ 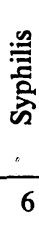 } \\
\hline Alcỏholic & . & . & . & . & & & & & & & & & & & \\
\hline Non-alcoh & olic & $\therefore$ & . & . & - & 66 & 23 & 43 & 28 & 38 & 22 & 44 & 28 & 20 & 18 \\
\hline Brothel & . & $\therefore$ & . & . & 9 & 23 & 32 & - & 19 & 13 & 24 & 8 & 17 & 7 & 8 \\
\hline Casual & . & . & . & . & 52 & 43 & - & 95 & 21 & 74 & 9 & 86 & 43 & 36 & 16 \\
\hline Condom & . & . & $\cdots$ & . & 12 & 28 & 19 & 21 & 40 & - & 18 & 22 & 21 & 10 & 9 \\
\hline Not conde & & . & $\ldots$ & $\ldots$ & 49 & 38 & 13 & 74 & - & 87 & 15 & 72 & 39 & 33 & 15 \\
\hline Preventive & ablu & & . & . & 11 & 22 & 24 & 9 & 18 & 15 & 33 & - & 21 & 6 & 6 \\
\hline Not preve & ative & plution & $\ldots$ & . & 50 & 44 & 8 & 86 & 22 & 72 & - & 94 & 39 & 37 & 18 \\
\hline Venereal s & ore & .. & . & . & 32 & 28 & 17 & 43 & 21 & 39 & 21 & 39 & 60 & 0 & 0 \\
\hline Gonorrhœ & & . & . & . & 23 & 20 & 7 & 36 & 10 & 33 & 6 & 37 & 0 & 43 & 0 \\
\hline Syphilis & . & $\cdots$ & .. & . & 6 & 18 & 8 & 16 & 9 & 15 & 6 & 18 & 0 & 0 & 24 \\
\hline
\end{tabular}

no condom, brothel exposure; (ii) not in alcoholics, syphilis, used preventive ablution, used condom, casual exposure, etc.) is obviously very large. On the other hand many such groups of patients would clearly be too small for conclusions to be drawn from the relative numbers of patients in them. We have therefore recorded the numbers of patients falling into the various salient groups, and used the chi-square test to determine whether such differences amongst the numbers as we find would be likely to result from chance alone or whether, on the other hand, some systematic cause is probably indicated.

In accordance with some recent practice, we have permitted ourselves to use the chi-square test down to an expected frequency of 3 ; and, in the two by two tables correction for continuity has been applied only where it is recorded. There is little doubt that further significant information is embedded in the material, and we hope to elicit this information by further analysis at a later date.

Data and Results.-The main data are set out in Table I. The table is symmetrical about the topleft to bottom-right diagonal, but both halves have been set out for the convenience of the eye in noting the totals of the various subgroups.

It will be seen from the two top-left entries that, of the 127 patients, 61 were alcoholic at the time of exposure and 66 were not. Moving down the diagonal, it is seen that 32 of the cases resulted from brothel exposure and that the remaining 95 resulted from casual exposure. And so on. The three bottom-right entries show that 60 of the patients contracted venereal sore, 43 gonorrhœa, and 24 syphilis. No patient contracted more than one of these three diseases.

Alcohol and Type of Exposure.-Abstracting from Table I the figures for brothel-casual: alcoholic-nonalcoholic, we obtain Table II. It will be seen that

TABLE II

ALCOHOL AND RELATION TO TYPE OF EXPOSURE

\begin{tabular}{cc|c|c|c}
\hline & & Brothel & Casual & Total \\
\hline Alcoholic &.. & 9 & 52 & 61 \\
\hline Non-alcoholic &.. & 23 & 43 & 66 \\
\hline Total $\ldots$ &.. & 32 & 95 & 127 \\
\hline
\end{tabular}

whereas the casual exposures are divided between alcoholic and non-alcoholic in the ratio of 52 to 43 , amongst the brothel exposures the non-alcoholics outnumber the alcoholics by more than two to one. The contrast is shown to be statistically significant by chisquare (corrected for continuity) $=$

$$
5.77,1 \text { d.f., } 0.02>P>0.01 \text {, }
$$

which shows that the probability (P) of such a sharp contrast having arisen by chance alone is something between one in a hundred and two in a hundred. 
The conclusion is that the test gives significant evidence that an alcoholic condition at the time of exposure is less prevalent amongst those infected in the brothel than amongst those infected as a result of casual exposure.

Condom and Type of Exposure.-Similarly abstracting from Table I the figures for brothel-casual : condom-no condom, we obtain Table III. The striking feature in

TABLE III

CONDOM AND RELATION TO TYPE OF EXPOSURE

\begin{tabular}{cc|c|c|c}
\hline & & Brothel & Casual & Total \\
\hline No condom & $\ldots$ & 13 & 74 & 87 \\
\hline Condom & $\ldots$ & 19 & 21 & 40 \\
\hline Total.. & $\ldots$ & 32 & 95 & 127 \\
\hline
\end{tabular}

this case is the relatively large number of casuals who used no condom. The contrast is shown to be statistically significant by chi-square (corrected for continuity) $=$

$$
\text { 13.73, } 1 \text { d.f., } P<0.001 \text {. }
$$

The conclusion is, again as might have been expected, that the test gives highly significant evidence that failure to use a condom is more prevalent amongst those infected by casual exposure than amongst those infected in the brothel.

Preventive Ablution and Type of Exposure.-Abstracting from Table I the figures for brothel-casual : preventive ablution-not preventive ablution, we obtain Table IV.

TABLE IV

PREVENTIVE ABLUTION AND TYPE OF EXPOSURE

\begin{tabular}{ll|c|c|c}
\hline & Brothel & Casual & Total \\
\hline $\begin{array}{l}\text { No preventive } \\
\text { ablution }\end{array}$ & $\ldots$ & 8 & 86 & 94 \\
\hline $\begin{array}{c}\text { Preventive ablution } \\
\text { Total .. }\end{array}$ & 24 & 9 & 33 \\
\hline
\end{tabular}

It will be seen that 24 out of the 32 patients infected in the brothel had used preventive ablution, and that 86 of the 95 patients infected casually had not done so. The contrast is shown to be statistically significant by chi-square (corrected for continuity) $=$

$$
\text { 50.09, } 1 \text { d.f., } P<0.001 \text {. }
$$

The conclusion is that the test gives highly significant evidence that failure to use preventive ablution is more prevalent amongst patients infected by casual exposure than amongst those infected in the brothel.

Any Prophylaxis and Type of Exposure.-From figures to be presented in Table VIII below we compile Table V.
The contrast is shown to be statistically significant by chi-square (corrected for continuity) =

$$
\text { 23.06, } 1 \text { d.f., } P<0.001 \text {. }
$$

The conclusion is that the test gives highly significant evidence that the use of neither preventive ablution nor condom (as opposed to the use of at

TABLE V

ANY PROPHYLAXIS AND TYPE OF EXPOSURE

\begin{tabular}{c|c|c|c}
\hline & Brothel & Casual & Total \\
\hline $\begin{array}{l}\text { Neither preventive } \\
\text { ablution nor } \\
\text { condom used . }\end{array}$ & 6 & 66 & 72 \\
\hline $\begin{array}{l}\text { Either preventive } \\
\text { ablution or con- } \\
\text { dom or both used }\end{array}$ & 26 & 29 & 55 \\
\hline Total .. & 32 & 95 & 127 \\
\hline
\end{tabular}

least one of the two) is more prevalent amongst patients infected as a result of casual exposure than amongst those infected in the brothel.

Relation of Alcoholism to Use of Condom.-We now return to Table III, and, referring to the primary data not presented in this report, we divide the 95 casual exposures and the 32 brothel exposures into those who were and those who were not alcoholic at the time of exposure. This is with a view to studying, amongst the casual and brothel exposures separately, the relation between the use, or not, of a condom and the being, or not, alcoholic at the time of exposure. We obtain Table VI.

\begin{tabular}{|c|c|c|c|c|c|}
\hline & & \multicolumn{2}{|c|}{$\begin{array}{c}\text { Casual } \\
\text { exposures }\end{array}$} & \multicolumn{2}{|c|}{$\begin{array}{c}\text { Brothel } \\
\text { exposures }\end{array}$} \\
\hline & & $\begin{array}{l}\text { No } \\
\text { alcohol }\end{array}$ & Alcohol & $\begin{array}{l}\text { No } \\
\text { alcohol }\end{array}$ & Alcohol \\
\hline Condom & . & 15 & 6 & 13 & 6 \\
\hline No condom & . & 28 & 46 & 10 & 3 \\
\hline . & & \multicolumn{2}{|c|}{$\begin{array}{l}\text { Chi-square (cor- } \\
\text { rected for con- } \\
\text { tinuity) }=6 \cdot 16 \text {, } \\
1 \text { d.f., } 0.02>P \\
>0.01 \text {. }\end{array}$} & \multicolumn{2}{|c|}{$\begin{array}{l}\text { Chi-square (cor- } \\
\text { rected for con- } \\
\text { tinuity) }=0 \cdot 16 \text {, } \\
1 \text { d.f., } 0.70>\mathrm{P} \\
>0.50 \text {. }\end{array}$} \\
\hline
\end{tabular}

TABLE VI

RELATION OF ALCOHOLISM TO USE OF CONDOM

The conclusions are that, for patients infected by casual exposure, the test gives significant evidence that failure to use a condom is more prevalent amongst those who were alcoholic than amongst those who were not ; but that, for patients infected in the brothel, the test gives no significant evidence one way or the other. 
Relation of Alcoholism to $U$ se of Preventive Ablution.Returning now to Table IV, and referring again to the primary data, we present the corresponding figures for those who did, and for those who did not, use preventive ablution (Table VII).

TABLE VII

RELATION OF ALCOHOLISM TO USE OF PREVENTIVE ABLUTION

\begin{tabular}{c|c|c|c|c}
\hline & $\begin{array}{c}\text { Casual } \\
\text { exposures }\end{array}$ & \multicolumn{2}{c}{$\begin{array}{c}\text { Brothel } \\
\text { exposures }\end{array}$} \\
\cline { 2 - 5 } & $\begin{array}{c}\text { No } \\
\text { alcohol }\end{array}$ & Alcohol & $\begin{array}{c}\text { No } \\
\text { alcohol }\end{array}$ & Alcohol \\
\hline $\begin{array}{c}\text { No preventive } \\
\text { ablution }\end{array}$ & 39 & 47 & 5 & 3 \\
\hline $\begin{array}{c}\text { Preventive } \\
\text { ablution }\end{array}$ & $\ldots$ & 5 & 18 & 6 \\
\hline
\end{tabular}

The conclusions are that, for patients infected by casual exposure, the test gives no significant evidence that failure to use preventive ablution is more (or less) prevalent amongst those who were alcoholic than amongst those who were not; and that for patients infected as a result of brothel exposure, the numbers are too small for the chi-square test to be applied.

Type of Prophylaxis and Type of Disease--Referring again to the primary data, we present the numbers of patients infected by casual exposure and the numbers of patients infected by brothel exposure who used preventive ablution only, condom only, both, and neither, in relation to each of the three diseases contracted.

Relative Incidence of Various Diseases.-We proceed to study the relative incidences of venereal sore, gonorrhoe, and syphilis, and in the first place we do so amongst casual exposures, regardless of whether or not prophylactics were used.

Testing the hypothesis that the figures $43,36,16$, in Table VIII, are a sample from a uniform distribution of the three diseases amongst the patients, we obtain :

$$
\text { chi-square }=12.4,2 \text { d.f., } 0.01>\overline{\mathrm{P}}>0.001 \text {. }
$$

The conclusion= is that the test gives highly significant evidence that the incidences of the three diseases amongst patients infected as a result of casual exposure are not all the same, and that consequently our best estimate at present is that the incidences are in the proportion 43 of venereal sore to 36 of gonorrhoea to 16 of syphilis.

Amongst brothel exposures, testing the hypothesis that the figures $17,7,8$, in Table VIII, are a sample from a population of patients with equal numbers suffering from each of the three diseases, we obtain :

chi-square $=5 \cdot 69,2$ d.f., which lies between $4 \cdot 61$ for $\mathbf{P}=\mathbf{0 . 1 0}$ and 5.99 for $\mathbf{P}=\mathbf{0 . 0 5}$, and therefore falls short of statistical significance at the 5 per cent. level. The relatively high frequency (17) of venereal sore is nevertheless suggestively large, and it will be noticed that, as for the casual exposures, venereal sore has the largest frequency of the three diseases.

The conclusion is that the high incidence of venereal sore relative to the incidences of gonorrhcea and of syphilis in the sample of patients infected by brothel exposure is suggestively large, but falls short of significance at the 5 per cent. level.

Comparing the two sets of figures $43,36,16$, and 17 , 7,8 , in Table VIII, we obtain :

$$
\text { chi-square }=2 \cdot 97,2 \text { d.f., } 130>P>0 \cdot 20 \text {. }
$$

The conclusion is that the test gives no significant evidence of difference amongst the relative incidences of the three diseases in patients infected casually on the one hand and in patients infected in the brothel on the other hand.

We now study the relative incidence of venereal sore, gonorrhóa, and syphilis amongst patients who used neither preventive ablution nor condom.

Amongst casual exposures, testing the hypothesis that the figures $26,30,10$, in Table VIII, are a sample from a population of patients with equal numbers suffering from each of the three diseases, we obtain :

$$
\text { chi-square }=10 \cdot 18,2 \text { d.f., } 0.01>P>0.001 \text {. }
$$

\begin{tabular}{|c|c|c|c|c|c|c|c|c|}
\hline \multirow{2}{*}{$\begin{array}{c}\text { Prophylactics } \\
\text { used }\end{array}$} & \multicolumn{4}{|c|}{ Casual Exposures } & \multicolumn{4}{|c|}{ Brothel Exposures } \\
\hline & Venereal Sore & Gonorrhœa & - Syphilis & Total & Venereal Sore & Gonorrhœa & Syphilis & Total \\
\hline Both .. & 1 & 0 & 0 & 1 & 9 & 4 & 4 & 17 \\
\hline P.A. only $\cdots$ & 7 & 0 & 1 & 8 & 4. & 2 & 1 & 7 \\
\hline Condom only & 9 & 6 & 5 & 20 & 2 & 0 & 0 & 2 \\
\hline Neither & 26 & 30 & 10 & 66 & 2 & 1 & 3 & 6 \\
\hline Total & 43 & 36 & 16 & 95 & -17 & 7 & 8 & 32 \\
\hline
\end{tabular}

TABLE VIII

DISEASE CONTRACTED IN RELATION TO TYPE OF PROPHYLACTIC 
The conclusion is that the test gives highly significant evidence that the incidences of the three diseases amongst patients who were infected as a result of casual exposure and who used neither preventive ablution nor condom are not all the same, and that our best estimate at present of the relative incidences of the diseases is 26 of venereal sore to 30 of gonorrhœa to 10 of syphilis.

Amongst brothel exposures the numbers $(2,1,3)$ in Table VIII are too small to enable a chi-square test to be made.

Again the numbers $(2,1,3)$ in Table VIII are too small to enable a comparison by means of the chi-square test to be made between casual and brothel exposures.

Prophylaxis and Type of Exposure.-We now analyse the use of preventive ablution only, condom only, both, and neither amongst patients infected casually and amongst patients infected in the brothel. Table VIII shows the number of patients in each of the eight groups. The most noticeable contrast is that, whereas a large proportion (66 out of 95) of the patients infected as a. result of casual exposure used neither of the two prophylactics, a large proportion (1.7 out of 32) of the patients infected in the brothel used both.

Comparing the two sets of figures $1,8,20,66$, and $17,7,2,6$, we obtain :

$$
\text { chi-square }=63.35,3 \text { d.f., } \mathrm{P}<0.001 \text {. }
$$

The conclusion is that the test gives highly significant evidence that the use of preventive ablution only, condom only, both and neither are not all of the same relative frequencies amongst patients infected casually on the one hand and amongst patients infected in the brothel on the other - the most striking contrast being between the high proportion of patients infected casually who use neither and the high proportion of patients infected in the brothel who use both.

Relative Effects of the two Prophylactics.-Amongst casual exposures, amongst patients who used condom only, we test the hypothesis that the figures $9,6,5$, and $26,30,10$, in Table VIII, are samples from two populations with the same relative incidences of the three diseases. We obtain :

$$
\text { chi-square }=1 \cdot 85,2 \text { d.f., } 0 \cdot 50>\mathrm{P}>0 \cdot 30 \text {. }
$$

Also, combining the cells for gonorrhœa and syphilis, we obtain :

$$
\text { chi-square }=0.20,1 \text { d.f., } 0.70>P>0.50,
$$

the chi-square not having been corrected for continuity.

The conclusion is that the tests give no significant evidence that for casually infected patients there is a difference in the relative incidences of the three diseases in patients who used condom only on the one hand and in patients who used neither preventive ablution nor condom on the other hand.

Amongst patients who used preventive ablution only, because of the smallness of the numbers $7,0,1$, and 26 ,
30,10 , in Table VIII, we have to combine the cells for gonorrhœa and syphilis. Testing the hypothesis that the numbers 7,1 , and 26,40 are samples from two populations with the same relative incidences of venereal sore on the one hand and gonorrhœa or syphilis pooled on the other, we obtain chi-square (corrected for continuity) $=$

$$
4 \cdot 88,1 \text { d.f., } 0.05>P>0.02 \text {. }
$$

The conclusion is that the test gives significant evidence that for casually infected patients the incidence of venereal sore in relation to that of gonorrhœa and syphilis pooled is larger amongst patients who used preventive ablution only than amongst patients who used neither preventive ablution nor condom. If it be assumed that apart from the use or not of preventive ablution the two groups of patients were exposed to equal relative risks of infection by venereal sore on the one hand and by gonorrhœa and syphilis pooled on the other hand, it may be inferred that preventive ablution is less effective against venereal sore than against syphilis and gonorrhœa (pooled) amongst casual exposures.

When preventive ablution only and condom only are compared, because of the smallness of the numbers $7,0,1$, and $9,6,5$, in Table VIII, we have to combine the cells for gonorrhœa and syphilis. Testing the hypothesis that the numbers 7,1 , and 9,11 are samples from two populations with the same relative frequencies of venereal sore on the one hand and gonorrhoea and syphilis pooled on the other hand, we obtain chi-square (corrected for continuity) $=$

$$
2 \cdot 66,1 \text { d.f., } 0 \cdot 20>P>0 \cdot 10 \text {. }
$$

The conclusion is that the test does not give significant evidence of different relative incidences of venereal sore on the one hand and of gonorrhœa and syphilis (pooled) on the other hand amongst casually infected patients who used preventive ablution only and who used condom only.

Amongst brothel exposures the numbers are too small to enable comparisons to be made.

Venereal Disease amongst Brothel Users.-Figures supplied by the military authorities show that, during the period under review (two months) 88,682 men used the brothel (a man who used the brothel more than once counting as a separate man on each occasion), and of these, 77,618 used the preventive ablution room.

On general grounds we may assume that the majority of infected men amongst these two groups came to the hospital for treatment. Abstracting the necessary figures from Table VIII, we may therefore draw up Table IX.

Comparing the incidences 0.310 per thousand and 0.723 per thousand, we obtain :

$$
\text { chi-square }=4.60,1 \text { d.f., } 0.05>P>0.02 \text {. }
$$

The conclusion is that the test gives significant evidence that the incidence of the three venereal 
TABLE IX

INCIDENCE OF VENEREAL DISEASE AMONG BROTHEL USERS

\begin{tabular}{|c|c|c|c|c|c|c|}
\hline & & Used brothel & $\begin{array}{l}\text { Used preventive } \\
\text { ablution room }\end{array}$ & $\begin{array}{l}\text { Incidence } \\
\text { per } 1,000\end{array}$ & $\begin{array}{c}\text { Not used } \\
\text { preventive } \\
\text { ablution room }\end{array}$ & $\begin{array}{l}\text { Incidence } \\
\text { per } 1,000\end{array}$ \\
\hline Uninfected .. & . & 88,650 & 76,594 & - & 11,065 & - \\
\hline $\begin{array}{l}\text { Infected with: } \\
\text { Venereal sore } \\
\text { Gonorrhœa } \\
\text { Syphilis ... }\end{array}$ & $\begin{array}{l}\ldots \\
\cdots \\
\ldots\end{array}$ & $\begin{array}{r}17 \\
7 \\
8\end{array}$ & $\begin{array}{r}13 \\
6 \\
5\end{array}$ & $\begin{array}{l}0.168 \\
0.077 \\
0.064\end{array}$ & $\begin{array}{l}4 \\
1 \\
3\end{array}$ & $\begin{array}{l}0.362 \\
0 \cdot 090 \\
0 \cdot 272\end{array}$ \\
\hline Sub-total & . & 32 & 24 & 0.310 & 8 & 0.723 \\
\hline Total $\quad$. & .. & 88,682 & 77,618 & - & 11,064 & - \\
\hline
\end{tabular}

diseases (pooled) is smaller amongst users of the brothel who used the preventive ablution room than amongst users of the brothel who did not use the preventive ablution room. Our only estimates, which are approximate ones, of these incidences are 0.310 per thousand for the former group and 0.723 for the latter. It cannot, of course, be assumed that the difference between these two incidences is due solely to the use of preventive ablution, as we have no record of the numbers of uninfected men in either group who used a condom.

\section{Summary of Statistical Analysis}

A large proportion of the patients who presented themselves for treatment at the venereal disease department of a military hospital during a period of two months provided information as to whether they were infected casually or in the officially recognized brothel, whether or not they were alcoholic at the time of exposure, and whether they used preventive ablution, condom, both, or neither.

A statistical analysis of the figures shows that :

1. In comparison with brothel exposures, casual exposures tended to be alcoholic, without condom, without preventive ablution, and with neither condom nor preventive ablution.

2. Amongst casual exposures, alcoholic exposures tended to be without condom, although the same number of cases failed to give significant evidence of a similar tendency with regard to the use, or not, of preventive ablution.

3. Amongst casual exposures, the incidences of venereal sore, gonorrhœa, and syphilis are not all the same, that of syphilis tending to be relatively low, according to the only estimate we have. A tendency in brothel exposures for the incidence of venereal sore to be high relative to the incidences of gonorrhœa and of syphilis is less pronounced, and falls short of statistical significance:

A direct comparison between the casual and brothel exposures with regard to the relative incidences of venereal sore and gonorrhœa and syphilis gives no significant evidence of difference.

4. Amongst casual exposures who used neither preventive ablution nor condom, the incidences of venereal sore, gonorrhœa, and syphilis are not all the same, that of syphilis being the lowest according to the only estimate we have.

5. There is a strong tendency for brothel exposures to use both prophylactics and for the casual exposures to use neither.

6. For casual exposures the figures give no significant evidence that the relative incidences of venereal sore, gonorrhœa, and syphilis are not the same amongst those who used neither preventive ablution nor condom as amongst those who used condom only ; but they do give significant evidence of difference between those who used preventive ablution only and those who used neither. The difference is that venereal sore is relatively higher amongst those who used preventive ablution only ; so that if the effect is a causal one, preventive ablution is less effective against venereal sore than against gonorrhœa or syphilis pooled.

7. A direct comparison of those who used preventive ablution only and those who used condom only with respect to the relative incidences of venereal sore, gonorrhœa, and syphilis does not show significant evidence of difference, though this may be due to the smaller numbers of cases available than for the above.

8. The absolute incidence of all three forms of venereal disease pooled is estimated to be 0.310 per thousand amongst those who used the preventive ablution room and 0.723 per thousand amongst those who did not. The difference is statistically significant, but it cannot be said how much of the difference is due actually to the use of preventive ablution as it is not known how many men in each of the two groups used a condom. 


\section{Discussion}

The results given under "Statistical Analysis: Data and Results" (above) demand comments.

The association of casual fornication with alcoholic indulgence is widely accepted, and in this series over half of the men casually exposed had been drinking; it can hardly be doubted that alcohol played some part in making them more likely to yield to temptation. Among brothel exposures, however, alcoholism was much less frequent, and it must be concluded that by no means all men had their moral rectitude so undermined. This was in fact strikingly evident to one who observed the brothel in action. The deliberate process of " booking in" already described was not such as to appeal to a man acting on momentary impulse.

There was not to the best of my belief any general distrust or dislike of the brothel among the troops, and it seems likely that very many men, setting out from camp with the intention of fornication, chose the brothel as providing the most convenient and safe opportunity. Others, with no such intention at the outset, fell into temptation after alcohol, when caution had gone to the winds, and they did not bother in this state to seek out the brothel. The popularity of the brothel among men who had not been drinking indicates that there existed a "hard core," by no means few in number, who indulged in promiscuity without the intervention of momentary temptation and presumably as a normal part of the lives they were leading at the time. Information 1 obtained from a different source suggests that promiscuity was more common in that theatre of war than among the same men in their home country; boredom was prevalent, and it was astounding to find that among men infected with venereal disease nearly a half were under the impression that coitus was necessary to the maintenance of good health.

Prophylaxis (preventive ablution, condom, or both) was more frequently carried out by those using the brothel. To some extent this may be related to the alcoholic carefree state of the casual exposure, and this factor is brought out in relation to the use of condom in casual exposures. Men who had taken alcohol were less likely to use a condom than those who had not. Here again a man who had not taken alcohol, whose exposure we may consider to be more premeditated, is more likely to have provided himself with a condom beforehand and, having it, is more likely to have the patience to use it.

The same tendency regarding alcoholism is not ascertainable in respect of preventive ablution in casual exposures or of either form of prophylactics in the brothel. In the case of preventive ablution this is not surprising ; for casual exposures preventive ablution was relatively unavailable, whatever the man's wishes ; in the brothel it was so readily available that a man who was tipsy was shepherded along to the preventive ablution room with the rest, where he carried out ablution under supervision and was hardly less likely to do so than the sober.

While casual exposures are almost uncontrollable as regards prophylactics, it was believed that preventive ablution could be " pushed" in the brothel and to a less extent the use of condoms also. These figures seem to substantiate this belief. No information is available as to the proportion of casual exposures who used prophylactics, regardless of whether they became subsequently infected or not. In the brothel, however, over the first eight months of the year 89 per cent. of all men used preventive ablution. Of the men dealt with in the detailed analysis, 87.5 per cent. used preventive ablution.

The incidence of venereal diseases in the brothel exposures calls for comment. In this enquiry some cases of venereal diseases probably went unrecorded either because the disease was concealed, or because the man left the district during his incubation period. On the other hand it is likely that some men claimed a brothel infection when they had really been infected elsewhere. Admitting, however, that the true incidence of venereal disease in the brothel was perhaps greater than is recorded, it is still amazingly low. Over the first eight months of the year the total incidence was 0.31 per thousand; over the two months analysis, 0.36 per thousand. Incidence rates ten times this would still be surprisingly low.

The low rate of infection is no doubt due partly to preventive ablution, but even when no preventive ablution was used it rose to a mere 0.723 per thousand. This low incidence is presumably to be attributed to the general conduct of the brothel, to the inspection and medical supervision of the women, and to the limitation of its clientele to service personnel. The latter factor was no doubt of great importance. All service men known to be infected were kept in hospital; those who were concealing their disease were hardly likely to court discovery and punishment by frequenting the semiofficial brothel where military police were on duty.

The brothel owed its existence to the belief that "safe" prostitution can be provided and to the hope that, if it were, the incidence of venereal disease in a fighting force would be reduced. The corollary is open to question and cannot be discussed here ; neither can the moral issues involved : but these figures do indicate that medically "safe" fornication can be provided.

An attempt was made to examine the effectiveness 
of preventive ablution. The reduction of the total venereal disease rate from 0.723 per thousand to 0.310 per thousand has been shown. This reduction may not be due entirely to. the use of preventive ablution since the simultaneous effect of condoms cannot be assessed. It is noticeable (Table I) that the failure to use preventive ablution goes with the failure to use a condom.

It was hoped that it would be possible to assess the value of preventive ablution in relation to the different diseases. A cursory examination of the figures was made, but statistical analysis has shown that for the most part numbers are too small for conclusions to be drawn. Amongst casual exposures, however, the relative incidence of venereal sore as compared with gonorrhœa and syphilis was significantly high after preventive ablution; as the effect of preventive ablution is to reduce the total venereal disease rate, this means that gonorrhœea and syphilis are reduced more than venereal sore, that is, that preventive ablution is more effective against gonorrhœa and syphilis than it is against venereal sore. In the brothel, where preventive ablution was much more frequent than elsewhere, the relative incidence of venereal sore seems to have been higher than among casual exposures. This would bear out the conclusion that venereal sore is relatively resistant to preventive ablution, but these figures, though suggestive, do not pass a strict statistical test.

It will, of course, be noted that the circumstances, both medical and legal, in which these brothels were conducted were exceptional and incapable of ready adaptation to normal civilian conditions. For this reason the conclusions quoted cannot be held to support a medical argument for controlled prostitution in general.

It remains to comment on the relative rarity of notified contacts being in fact found to suffer from the disease. In every case those who had no clinical signs and passed the prescribed tests were allowed to continue work without treatment. None of them infected any other men. This raises the question whether such women carried infection for a short time (minutes or hours) and were able to pass it on without themselves being infected. This is the inevitable conclusion if our patients were truthful in denying any infective contact other than the one in question. This conclusion is supported by the fact that it was rare for two or more men to claim infection from the same source. A glance at the figures will show that each woman averaged thirty clients a day; or more; during the three to five days of incubation of gonorrhoa or chancroid, a hundred men might well have been exposed to infection before the woman was known to be suffering from the disease. Yet rarely, if at all, was more than one man infected. It seems most likely that infective material from one client affected the next and was then removed by the woman in the course of her own prophylaxis; perhaps these women, exposed to risks so often, had a partial degree of immunity. Alternatively, we might conclude that venereal diseases are considerably less infectious than we usually suppose, particularly if the woman has a high standard of local hygiene.

The last alternative is that in fact our patients falsely claimed this source of infection; if this explanation is correct the incidence of venereal disease contracted in the brothel must have been even less than that recorded. This last explanation cannot, I am sure, entirely account for the circumstances.

\section{Summary}

1. The organization of a brothel is described, with particular reference to medical arrangements.

2. Preventive ablution was provided and was used by nearly 90 per cent. of men using the brothel.

3 . In the brothel the incidence of venereal diseases among male clients was between 0.3 and 0.4 per 1,000. Among men who did not use preventive ablution this rate was approximately doubled.

4. Indulgence in alcohol did not seem to be: frequent in men visiting the brothel.

5. Compared with the above, men exposed to. casual and clandestine infection had more often been drinking; and they used prophylactic measures less. frequently.

6. Preventive ablution seemed to be more effective against gonorrhœa and syphilis, taken together, than against venereal sore.

7. The facts seem to indicate that prostitutes may have caused infection for short periods without. themselves becoming infected. 